Pure Sciences

Poster

Abstract ID: 97

\title{
Preliminary phytochemical screening and antibacterial activity of methanol and ethylacetate fractions from Glochidion superbum's leaves extract
}

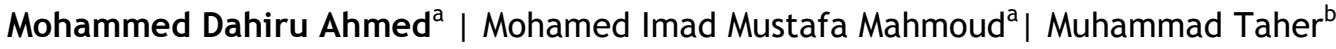 \\ ${ }^{a}$ Department of Basic Medical Sciences, Kulliyyah of Medicine, International Islamic University \\ Malaysia \\ ${ }^{b}$ Department of Pharmaceutical Technology, Kulliyyah of Pharmacy, International Islamic \\ University Malaysia
}

Introduction: The leaves of Glochidion superbum and other similar plants had been in use as a folk medicine by indigenous people in South East Asia for treatment of wound infections and diarrhoea. As recommended by WHO, studies on medicinal plants should include both identification of the chemical constituents and determination of their biological activities. Thus, the study aims to screen various local plant extracts for antibacterial activity and determine the extract fraction showing the highest antibacterial activity. Methods: In this study, Glochidion superbum leaves methanol extract was selected after preliminary antibacterial screening of this extract alongside extracts of Rennellia elliptica (leaves and roots) and Uncaria acida (stem and leaves) by the agar disc diffusion method against Escherichia coli ATCC 35218, Pseudomonas aeruginosa ATCC 27853, Staphylococcus aureus ATCC 25923, and Bacillus subtilis ATCC 11778. Furthermore, methanol leave extract of Glochidion superbum was subjected to a qualitative phytochemical screening. The extract was fractionated using Vacuum Liquid Chromatography (VLC) method and the following fractions were obtained: methanol $2.2 \mathrm{~g}$ (4.7\%), ethylacetate $38.3 \mathrm{~g}(81.4 \%)$ and ethylacetate:methanol $5.0 \mathrm{~g}(10.6 \%)$. Results: The ethylacetate:methanol 1:1 fraction showed the highest in vitro dose-dependent inhibitory activity at concentrations of $25,50,100$ and $150 \mathrm{mg} / \mathrm{mL}$ against the growth of $E$. coli ATCC 35218, and S. aureus ATCC 25923. Conclusions: This research has demonstrated proof of concept that the plant extract of Glochidion superbum leaves has antibacterial activity against both gram-positive and gram-negative bacteria.

KEYWORDS: Glochidion superbum, Screening, fractionations, antibacterial activity 